\title{
Treatment of Tobacco Dependence in People with Mental Health and Addictive Disorders
}

\author{
Kristen M. Mackowick, B.S. ${ }^{1}$, Marie-Josee Lynch, M.D. ${ }^{2}$, Andrea H. Weinberger, Ph.D ${ }^{3,4}$, \\ and Tony P. George, M.D., FRCPC 2,3 \\ ${ }^{1}$ Intramural Research Program, National Institute on Drug Abuse (NIDA), National Institutes of \\ Health (NIH), Baltimore, MD USA; Institute of Medical Sciences, University of Toronto, Toronto, \\ ON Canada \\ 2Division of Brain and Therapeutics, Department of Psychiatry, University of Toronto; \\ Schizophrenia Program, Centre for Addiction and Mental Health (CAMH), Toronto, ON Canada \\ ${ }^{3}$ Division of Substance Abuse, Department of Psychiatry, Yale University School of Medicine, \\ New Haven, CT USA \\ ${ }^{4}$ Cancer Prevention and Control Research Program, Yale Cancer Center, New Haven, CT USA
}

\begin{abstract}
People with mental health and addictive disorders (MHADs) have higher rates of cigarette smoking, and less success in quitting smoking compared to the general population. Moreover, tobacco-related medical illness may be the leading cause of death in the MHAD population. We discuss the scope of this comorbidity, and approaches to the treatment of tobacco dependence in people with MHAD, including schizophrenia, mood disorders, anxiety disorders, and alcohol and substance use disorders. Finally, at the level of health systems, we emphasize the importance of integrated treatment of tobacco dependence in MHADs.
\end{abstract}

\section{Keywords}

Mental health and addictive disorders; Nicotine dependence; Tobacco; Treatment; Smoking cessation; Psychiatric disorders; Schizophrenia; Anxiety disorders; Mood disorders; Substance use disorders; Alcoholism; Comorbidities; Pharmacotherapy; Integrated care

\section{Introduction}

Tobacco smoking is the leading preventable cause of death in the Western world [1,2], with a prevalence of $\sim 20 \%$ in the United States general adult population and nearly 450,000 deaths from tobacco-related illnesses each year [3]. Moreover, smoking prevalence in adults with mental health and addictive disorders (MHADs) can range from $50-85 \%$, and these smokers are 2-5 times less likely to quit than those in the general population [4-6].

Approximately $55 \%$ of smokers have ever met criteria for a psychiatric disorder [ $4 * *]$ and

Corresponding Author: Tony P. George, M.D., FRCPC Complex Mental Illness Program,, Centre for Addiction and Mental Health (CAMH) 250 College Street, Room CS 734 Toronto, Ontario CANADA M5T 1R8 Tel: (416) 535-8501, ext. 4544 Fax: (416) 979-4676 tony.george@ camh.ca.

Disclosure K. M. Mackowick: none; M. -J. Lynch: none; A. H. Weinberger: funding from NIDA (R03-DA027052); T. P. George: member of Novartis Data Monitoring Committee; consultant to Janssen-Ortho and Pfizer; payment for serving on speakers bureaus for Pfizer, AstraZeneca, and Janssen-Ortho; grants from National Institute on Drug Abuse, Canadian Institutes of Health Research, Ontario Mental Health Foundation, and Pfizer; royalties from Taylor \& Francis. 
these adults consume about 70\% of all cigarettes smoked in the United States [5]. Along with a propensity to smoke more heavily [4,7], smokers with MHADs are at a greater risk for medical morbidity and mortality. In 2009, tobacco-related illnesses, including chronic obstructive pulmonary disease, cardiovascular disease, and lung cancer, were the leading cause of death in MHAD populations whose life expectancies are considerably reduced compared to those in the general population [8-11].

While there has been progress in developing smoking cessation treatments for those with MHAD, long-term quit rates remain low. Lasser and colleagues [4**] found that quit rates for individuals with past month mental illness diagnoses ranged from $0.0 \%$ (schizophrenia) to $33.3 \%$ (simple phobia) compared to $42.5 \%$ for individuals without mental illness. The presence of MHAD may be a vulnerability factor for the initiation and maintenance of smoking as well as for the development of nicotine dependence, which may lead to a more difficult time quitting [12, 13**]. There is also evidence that those with MHADs experience enhanced nicotine withdrawal [14]. The poor long-term cessation rates in adults with MHADs highlight the need for developing better smoking cessation treatments in these populations.

This article reviews current research on tobacco treatment in people with MHADs, including the assessment of tobacco dependence in these patients, and recent controlled smoking cessation trials in schizophrenia, mood and anxiety, and substance use disorders. The safety and efficacy of these treatments will also be reviewed, as improving long-term quit rates without psychiatric symptom exacerbation or drug use relapse is an important consideration. Finally, the importance of integrated tobacco and MHAD treatment will be discussed.

\section{Assessment of Tobacco Dependence}

While there is evidence for high rates of tobacco dependence in MHADs, formal establishment of a tobacco dependence diagnosis is often overlooked in clinical settings [15]. For persons with MHADs, this is especially important because: 1) Many of these adults may qualify for a diagnosis of tobacco dependence, and; 2) Tobacco smoking may effect both the course of the psychiatric illness and the effectiveness of psychiatric treatment $[6,16,17]$.

Both routine questions about tobacco use (e.g., smoking rate, age of first cigarette, and age at the start of daily smoking) and commonly used self-report smoking measures with high reliability in smokers with MHADs [18] should be used when assessing tobacco use in adults with MHADs. Information related to the unique motivators of smoking for individuals with MHADs (e.g., amelioration of medication side effects, more intense tobacco craving and withdrawal, and cognitive deficits) should also be assessed. The patient's perceived benefits of smoking should be noted as well as perception of health risks associated with smoking, which could be a potential barrier to treatment and may impact their motivation to stop smoking. Kelly et al. [19*] found that adults with schizophrenia were less appreciative of the health risks associated with tobacco and were less motivated to quit than adults without schizophrenia. This study also noted that people with schizophrenia reported a greater motivation to quit smoking when faced with social pressure. These additional factors should be noted in any intake assessment, as they can be used to create a personalized treatment plan. 


\section{Current Smoking Cessation Treatments}

\section{Schizophrenia and Schizoaffective Disorder}

The most widely studied treatments for smokers with schizophrenia are Nicotine Replacement Therapies (NRTs), including transdermal nicotine patch (TNP), nicotine inhaler, gum, nasal spray and lozenges. NRTs appear safe to use for cessation in smokers with schizophrenia, but there are low rates of long-term abstinence [20-26]. Despite the demonstrated efficacy of the TNP in smoking cessation treatment in the general population, there are few controlled trials of NRT in smokers with schizophrenia, as NRTs are most commonly used in combination with other therapies, such as Cognitive Behavioral Therapy [CBT; 24, 27, 28] or other pharmacotherapies [e.g. bupropion; 24, 25].

In a study by George and colleagues [22], forty-five smokers with schizophrenia were randomized to either a specialized group therapy program (which emphasized motivational enhancement, relapse prevention, social skills training, and psychoeducation) or a group therapy program of the American Lung Association. All participants received 10 weeks of treatment with TNP $(21 \mathrm{mg} / \mathrm{day})$ and 10 weekly group therapy sessions. Pre-quit antipsychotics (ie, antipsychotic medications that had been prescribed prior to entry into the study) were continued for the duration of the study. Results showed that while smoking abstinence rates did not differ between the two behavioral treatment groups, those patients prescribed atypical antipsychotics (most notably risperidone and olanzapine) showed significantly higher rate of smoking abstinence (55.6\%) compared to those taking typical antipsychotics $(22.2 \% ; \mathrm{p}<0.01)$.

Sustained-release (SR) bupropion (Zyban $\left.{ }^{\circledR}\right)$, a first-line treatment for nicotine dependence, is safe and effective for smoking cessation [29]. To support the safety and efficacy of bupropion for use in smokers with schizophrenia, George and colleagues [30] randomized 32 smokers with schizophrenia to receive either bupropion SR (300mg/day) or placebo with weekly group therapy sessions. Fifty percent of those randomized to the bupropion group achieved biochemically-verified 7-day point prevalence smoking abstinence (expired carbon monoxide levels $<10 \mathrm{ppm}$ ) at the trial end point (Week 10), compared to $12.5 \%$ in the placebo group $(\mathrm{p}<0.05)$.

Two studies have tested the combination of NRT and bupropion in smokers with schizophrenia. Evins et al [24] studied 51 adult smokers with schizophrenia treated with bupropion SR versus placebo, nicotine inhaler (self-administered to reduce craving and withdrawal), and CBT for 12 weeks. Findings supported the superiority of the combination of bupropion and NRT versus placebo and NRT. Moreover, George and colleagues [25] demonstrated a significant increase in abstinence rates with the combination of bupropion SR and TNP $(21 \mathrm{mg})$ compared to placebo and TNP in 58 smokers with schizophrenia or schizoaffective disorder at the end of a 10-week trial, and with long-term abstinence at 26 weeks.

The nicotinic partial agonist varenicline (Chantix $®$ ) was approved as a first-line medication by the Food and Drug Administration (FDA) in 2006, and may be the most effective pharmacologic treatment for smoking cessation [31]. However, case reports of psychiatric symptom exacerbation have raised concern about its use [32,33]. Most recently, there has been significant interest in evaluating the safety and efficacy of varenicline in smokers with schizophrenia and schizoaffective disorder, as part of the FDA directive to establish the safety of this agent in MHADs. A recent multi-center study in 127 smokers with schizophrenia and schizoaffective disorder suggested the superiority of varenicline ( $2 \mathrm{mg}$ / day) versus placebo for short-term (12 weeks) smoking cessation outcomes, and also provided evidence that varenicline did not worsen psychotic symptoms or increase suicidal 
behaviors compared to placebo [34*]. Further research on the safety and efficacy of varenicline in MHADs using prospective randomized trials is needed.

\section{Anxiety Disorders}

Despite the fact that the prevalence of smoking across anxiety disorders ranges from $32 \%$ to $55 \%$ for current smokers and $45 \%$ to $77 \%$ for lifetime smokers [4] and that smoking may exacerbate anxiety symptoms [35-37*], few studies have addressed smoking cessation among these patients. Accordingly, smoking cessation treatment should be a top priority when treating an individual with an anxiety disorder.

Post-traumatic stress disorder (PTSD) is the most studied anxiety disorder in smoking cessation treatment. There is a $45 \%$ prevalence of current and $~ 58 \%$ prevalence of lifetime smoking in those with PTSD [4]. Smoking prevalence varies by combat exposure, with rates of 53-66\% [38-40], and higher smoking prevalence with higher combat exposure [41]. Hertzberg and colleagues [42] conducted one of the first randomized trials to evaluate bupropion SR for smoking cessation in combat veterans with PTSD. Ten participants received bupropion and 5 received placebo, as well as individual behavioral counseling for 12 weeks. Of those participants on bupropion, 70\% (7/10) completed treatment and 60\% were tobacco abstinent at Week 12. At 6-month follow-up, 40\% of participants on bupropion were abstinent. Only 20\% (1/5) of participants receiving placebo achieved abstinence.

One large multi-center trial has examined tobacco treatment in smokers with PTSD [43**]. Ten Veterans Administration sites included smokers who were already undergoing treatment for PTSD and were willing to receive smoking cessation treatment. Subjects were randomly assigned to receive integrated tobacco use treatment delivered by mental health providers or tobacco treatment delivered separately by cessation specialists. Subjects in the integrated care group received cessation medications (bupropion, nicotine patch, nicotine gum, and nicotine spray) from the mental health professional managing their PTSD treatment and behavioral counseling administered by case managers. Subjects in the separated treatment group received the same smoking interventions from staff members at a smoking cessation clinic. Participants in integrated care were twice as likely to achieve 7- and 30-day abstinence. This finding underscores the need for integrated smoking cessation treatment for those with MHADs [44].

\section{Mood Disorders}

There are relatively few studies of smoking cessation in people with mood disorders (unipolar depression and bipolar disorder). Smoking prevalence for past month major depression, dysthymia, and bipolar disorder are $44.7 \%, 38.2 \%$, and $60.6 \%$, respectively [4]. Fortunately, some of these individuals are willing to try to quit smoking (25\%) and will accept treatment for their tobacco dependence $[45,46]$. Smokers who are nicotine dependent are twice as likely as nonsmokers to have a history of depression [47], and those with a history of depression are three times as likely to progress to daily smoking [48] and report higher rates of smoking and nicotine dependence [5] than those without a history of depression. Smokers with a positive history for depression, compared to smokers without depression history, reported stronger beliefs that smoking reduces negative affect, boredom, and cravings, and that it increases social facilitation and stimulation [49]. These findings underscore the need not only for effective integrated mental health and smoking cessation treatment, but to treat these illnesses concurrently.

The majority of studies of smoking cessation treatment and depression include smokers with past major depression and few studies have examined individuals with current depression 
[37]. Most adult smokers with current depression are excluded from smoking cessation trials, which excludes up to $40 \%$ of smokers; this is a significant short-coming for the literature on tobacco dependence and depression. Further, smoking cessation studies that have included smokers with current depression have shown mixed results. Thorsteinsson and colleagues [50] examined depressive and withdrawal symptoms in non-medicated, adult smokers with current MDD. Participants were randomized to receive either active nicotine patches or placebo patches and the primary results showed that more participants in the placebo group than the active patch group resumed smoking after the quit date. Nicotine did not exert the expected antidepressant effects and depressive symptoms decreased among those who remained abstinent throughout the trial similarly for participants who did and did not receive nicotine. Evins and colleagues [51] randomized adult smokers with either current or past unipolar depression to receive bupropion or placebo with CBT and TNP and found that bupropion did not increase the efficacy of CBT and TNP, and did not prevent the increase in depressive symptoms associated with smoking abstinence. Hall and colleagues [52] found greater quit rates with nicotine patch and a staged care intervention relative to nicotine patch and a brief contact control condition. MacPherson and colleagues [53*] found that smokers receiving Behavioral Activation Therapy BAT and TNP were able to achieve higher rates of cessation than smokers receiving Cognitive-Behavioral Therapy (CBT) and TNP. Vickers et al. [54] built on the combination behavioral therapy and NRT by adding either exercise counseling sessions or health education sessions. There were no differences in abstinence rates between the two groups, but this remains an area that is open to future research.

There are also few studies utilizing non-nicotine pharmacotherapy (e.g. bupropion and varenicline) or behavioral treatments. In an open-label study by Philip and colleagues [55], the antidepressant effects of varenicline were assessed in adult smokers with treatmentresistant depression, by administering varenicline in addition to the participant's existing selective serotonin reuptake inhibitor (SSRI) treatment. Results show that there was a significant improvement in depressive symptoms at trial endpoint, and that $44 \%$ of participants achieved smoking abstinence. Furthermore, improvement in depressive symptoms was correlated with smoking cessation. Bupropion SR has also been shown to have similar effects, with a study by Chengappa et al [56] reporting 32\% of participants $(\mathrm{N}=25)$ abstinent at trial endpoint and no emergent depressive episodes in any participants. Trockel and colleagues [57] found that CBT improved smoking outcomes for cardiac patients with current major depression, dysthymia, or minor depression who also had social support, suggesting the importance of social support during quit attempts for smokers with current depressive disorders.

There have been only two small studies of smoking cessation in bipolar disorder. Weinberger et al. [58] reported a small randomized, placebo-controlled 10-week trial of bupropion SR in N=5 smokers with bipolar disorder, and showed that this agent was welltolerated and lead to reductions in smoking and abstinence in the active bupropion $(\mathrm{n}=2)$ versus placebo ( $\mathrm{n}=3$ ) group. Most recently, Wu et al. [59] using similar methodology as Weinberger et al [58], found that varenicline versus placebo was well-tolerated in smokers with bipolar disorder $(\mathrm{N}=5)$ and led to reductions in smoking over 10-weeks. More study of smoking cessation pharmacotherapies is urgently needed in people with bipolar disorder.

\section{Substance Use Disorders (SUDs)}

Individuals with substance use disorders (SUD) have the highest rates of tobacco use of any MHAD group, with prevalence in the range of 80-90\% [4]. Nonetheless, the literature on smoking cessation treatments for this population is relatively sparse. This group of patients presents a unique challenge due to the reciprocal craving-promoting effect between tobacco and other substances of abuse, such as alcohol and stimulants [60]. SUDs are also frequently 
associated with other psychiatric diagnoses, which themselves are risk factors for tobacco dependence [6].

Alcohol-Adults with alcohol use disorders are a high-risk population with high smoking rates of $\sim 68-76 \%$, and very low cessation rates of $8-17 \%[4,5]$. Both biological and psychological explanations have been suggested to explain this frequent comorbidity. Potential biological explanations involve common actions at the nicotinic acetylcholine receptor (nAChR), and psychological theories posit that both substances trigger cravings for the other as a result of them being frequently paired and thus acting as unconditioned stimuli [60].

A handful of studies have investigated the use of NRT, bupropion, and varenicline in alcohol dependent individuals. It has been demonstrated that NRTs are less effective in this population [61]. One hypothesis for this finding is that individuals with alcohol use disorders are more likely to smoke heavily and score higher on tobacco dependence measures, and consequently require higher doses of nicotine to achieve cessation. Kalman and colleagues tested this hypothesis in a study investigating the impact of higher doses of NRT on smoking cessation outcomes in a group of one hundred and thirty smokers who had achieved a minimum of 2 months of abstinence from alcohol [62]. The study participants were randomly assigned to two groups, and received either $21 \mathrm{mg}$ or $42 \mathrm{mg}$ TNP. Unexpectedly, they observed no significant differences in 7-day point prevalence abstinence rates between these groups at any of the follow-up points. Additionally, the 36-week cessation rates were disappointingly low, at $16.9 \%$ for the $21 \mathrm{mg}$ group and $9.2 \%$ for the 42 mg group.

A subsequent randomized double-blind placebo-controlled study by Kalman and colleagues assigned $\mathrm{N}=148$ smokers with recent abstinence from alcohol to receive TNP plus bupropion or nicotine patch plus placebo [63]. Group differences did not achieve statistical significance, and cessation rates at 24 weeks remained low at $6 \%$ for the bupropion group and $11 \%$ for the placebo group. These negative results were replicated in another placebocontrolled study of bupropion SR where the active treatment arm did not show an advantage to placebo in terms of long-term cessation outcomes in an alcohol-dependent population [64]. Thus, there does not appear to be a clear benefit of bupropion SR for smoking cessation in smokers in early alcohol dependence recovery.

It is important to note that all of the participants included in the above studies were abstinent from alcohol for less than one year, and were thus in the early stages of recovery. It has been shown that cessation rates for those with over a year of abstinence from alcohol approximate the rates of the general population [65**]. Thus, the very low smoking cessation rates found in the aforementioned studies could be due to the early stage of abstinence. This possibility speaks to the frequent clinical dilemma that surrounds the timing of smoking cessation efforts. There is often reluctance amongst clinicians to recommend smoking cessation in the context of early abstinence from alcohol due to concerns that quitting both alcohol and tobacco simultaneously may lead to relapse of alcohol use [66], given the additive stress of withdrawing from two separate highly addictive substances at once. A recent study comparing alcohol and tobacco quit rates when treatments for both were delivered at once versus sequentially (with a 6 month interval) failed to support this hypothesis [67]. Although there were no differences between the simultaneous and delayed groups in alcohol or tobacco cessation rates, the study had a remarkably high drop-out rate $(59.7 \%)$ for both treatment groups which may have confounded the results. However, one can tentatively infer from this well-controlled study that smoking cessation does not trigger alcohol relapse; however, a study by Joseph et al. [66] suggested that in a veterans sample of alcoholics, 
concurrent cessation of alcohol and tobacco was associated with a $30 \%$ increased risk of alcohol relapse compared to sequential quitting of alcohol and then tobacco.

Varenicline has recently been studied in this population as part of an open-label pilot study with the goal of establishing preliminary evidence of efficacy [68]. This 12-week trial involved $\mathrm{N}=32$ smokers with more than six months of sobriety from alcohol who received varenicline combined with behavioral counseling. The median duration of alcohol recovery was 29 months, much longer than in the Kalman et al. [62, 63] studies. The 7-day point prevalence abstinence rate at the end of the study period was $31 \%$. Although the drug was generally well-tolerated, 5 participants reported the emergence of clinically significant depressive symptoms. Although further controlled studies are required to establish the efficacy and tolerability of varenicline in this population, these results show promise, especially given that varenicline has been associated with a reduction in alcohol craving and heavy drinking [69].

Other SUDs-There are few published studies that have examined tobacco treatments for individuals with non-alcohol SUDs. A cross-sectional survey of 398 methadone maintenance patients in New York City sought to determine cigarette smoking patterns, readiness to quit, and interest in smoking cessation interventions in this population, which had an $83 \%$ smoking prevalence [70]. Twenty-two percent of the participants were in the preparation stage of readiness to quit smoking, and $48 \%$ were in the contemplative stage; $76 \%$ of participants expressed interest in an onsite smoking cessation program, which highlight the need for such interventions. A promising preliminary study compared varenicline to placebo for smoking cessation in 31 cocaine-abusing participants maintained on methadone for concurrent opioid dependence [71]. At the end of the 12-week follow-up period, those randomized to the varenicline group showed a $52.8 \%$ reduction in the number of cigarettes smoked per day compared to $8.0 \%$ in the placebo group $(\mathrm{p}<0.05)$. One placebo subject and two varenicline subjects reported no cigarette use in the last week of the study. There were no treatment-emergent adverse events. These results are encouraging, especially in the context of the lack of evidence of efficacy for other smoking cessation treatments (NRT, bupropion, contingency management and cognitive behavioral therapy) in methadone-maintained smokers [72].

\section{Conclusions}

It is clear that addressing tobacco dependence in adults with MHADs should be a priority for clinicians who work with these patients. However, this segment of the smoking population does not have easy access to treatment, as limited knowledge on how to engage these patients into treatment and the erroneous belief that quitting smoking may be harmful to symptoms and recovery is unfortunately widespread. Moreover, development of tobaccofree treatment and residential settings, despite considerable evidence that such tobacco bans motivate patients to seek tobacco treatment and lead to better patient outcomes [73], has shown little uptake and implementation in community settings. This is particularly unfortunate given that the leading cause of death in persons with comorbid MHADs appears to be tobacco-related medical illness [37, 73-76].

Fortunately, there is increasing evidence that standard pharmacological and behavioral treatments, with modest adaptations, can be used safely and effectively in mentally ill and addicted tobacco smokers. One important challenge from a services perspective is that there is rarely an integration of MHAD care with tobacco treatment services. The studies by McFall and colleagues [41, 43**] in smokers with PTSD have clearly demonstrated the importance of cross-training staff to deliver integrated tobacco and mental health care, and that this leads to better tobacco cessation and mental health treatment outcomes compared to 
when such treatments are delivered separately. The recent availability of non-nicotine pharmacotherapies (e.g. bupropion SR, varenicline) in various states such as New York and California is a fine example of how the science of tobacco addiction and tobacco control in collaboration with sound public policy making can lead to the broader insurance coverage of smoking cessation treatments, and their more widespread dissemination. Moreover, it will be important to ensure that while progress is being made with smokers in the general population, special populations, such as people with MHADs, who are known to be vulnerable to the initiation and maintenance of tobacco addiction are targeted, given their higher prevalence of tobacco use and dependence, less ability to quit smoking, and higher risk of morbidity and mortality. Clinicians need to become more proficient in asking about smoking behaviors in MHAD populations [6], and use stepped care approaches $[43,76]$ to ensure that treatment of tobacco smokers with mental illness and substance abuse is being sufficiently addressed.

\section{Acknowledgments}

This work was supported in part by the Chair in Addiction Psychiatry at the University of Toronto (to T. P. George), and grant support from the National Institute on Drug Abuse (NIDA; 2U01-DA-020830-07, to Caryn Lerman, Rachel Tyndale, and T. P. George; R03-DA027052, to A. H. Weinberger), the Canadian Institutes of Health Research (CIHR; MOP\#115145, to T. P. George), and the Ontario Mental Health Foundation (to T. P. George).

\section{References}

Papers of particular interest have been highlighted as:

- Of importance

•• Of outstanding importance

1. Giovino GA. The tobacco epidemic in the United States. Am J Prev Med. 2007; 33:318-326. [PubMed: 17888859]

2. CDC. Smoking-attributable mortality, years of potential life lost, and productivity losses-United States, 2000-2004. MMWR. 2008; 57:1226-28. [PubMed: 19008791]

3. Schroeder SA, Warner KE. Don't forget tobacco. New Engl. J. Med. 2010; 363:201-204. [PubMed: 20647196]

4 ••. Lasser K, Boyd JW, Woolhandler S, et al. Smoking and mental illness: A population-based prevalence study. J Am. Med Assoc. 2000; 284:2606-2610. An important population-based study of smoking prevalence in persons with and without current and past histories of mental illness based on data from the National Comorbidity Study (NCS), suggesting that persons with mental illness consume a disproportionate amount of cigarettes compared to the general population.

5. Grant BF, Hasin DS, Chou SP, Stinson FS, Dawson DA. Nicotine dependence and psychiatric disorders in the United States: Results from the National Epidemiologic Survey on Alcohol and Related Conditions. Arch. Gen. Psychiatry. 2004; 61:1107-1115. [PubMed: 15520358]

6. Hitsman B, Moss TG, Montoya ID, George TP. Treatment of tobacco dependence in mental health and addictive disorders. Can J Psychiatry. 2009; 54:368-378. [PubMed: 19527557]

7. Tidey JW, Rosenhow DJ, Kaplan GB, Swift RM. Subjective and physiological responses to smoking cues in smokers with schizophrenia. Nicotine Tob. Res. 2005; 7:421-429. [PubMed: 16085510]

8. Brown S, Inskip H, Barraclough B. Causes of excess mortality in schizophrenia. Br J Psychiatry. 2000; 177:212-217. [PubMed: 11040880]

9. Hennekens CH, Hennekens AR, Hollar D, et al. Schizophrenia and increased risk of cardiovascular disease. Am Heart J. 2005; 150:1115-1121. [PubMed: 16338246] 
10. Hser YI, McCarthy WJ, Anglin MD. Tobacco use as a distal predictor of mortality among longterm narcotic addicts. Prev Med. 1994; 23:61-69. [PubMed: 8016035]

11. Hurt RD, Offord KP, et al. Mortality following inpatient addictions treatment. Role of tobacco use in a community-based cohort. JAMA. 1996; 275:1097-1103. [PubMed: 8601929]

12. Morisano D, Bacher I, Audrain-McGovern J, George TP. Mechanisms underlying the co-morbidity of tobacco use in mental health and addictive disorders. Can J Psychiatry. 2009; 54:356-367. [PubMed: 19527556]

$13 \bullet \bullet$ Wing VC, Wass CE, Soh DW, George TP. A review of neurobiological vulnerability factors and treatment implications for comorbid tobacco dependence in schizophrenia. Ann N Y Acad Sci. 2012; 1248:89-106. [PubMed: 22129082] A recent review of neurobiological risk factors that predispose to the initiation and maintenance of tobacco dependence in people with schizophrenia.

14. Lo S, Heishman SJ, Raley H, et al. Tobacco craving in smokers with and without schizophrenia. Schizophr Res. 2011; 127:241-245. [PubMed: 20637571]

15. Montoya ID, Herbeck DM, Svikis DS, et al. Identification and treatment of patients with nicotine problems in routine clinical psychiatry practice. Am J Addict. 2005; 14:441-454. [PubMed: 16257881]

16. Berk M, Ng F, Wang WV, et al. Going up in smoke: Tobacco smoking is associated with worse treatment outcomes in mania. J Affect Dis. 2008; 110:126-134. 2008. [PubMed: 18280579]

17. Desai HD, Seabolt J, Jann MW. Smoking inpatients receiving psychotropic medications: A pharmacokinetic perspective. CNS Drugs. 2001; 15:469-494. [PubMed: 11524025]

18. Weinberger AH, Reutenauer EL, Allen TM, et al. Reliability of the Fagerstrom Test for Nicotine Dependence, Minnesota Nicotine Withdrawal Scale, and Tiffany Questionnaire for Smoking Urges in smokers with and without schizophrenia. Drug Alcohol Depend. 2007; 86:278-282. [PubMed: 16876968]

$19 \bullet$ • Kelly DL, Raley HG, Lo S, et al. Perception of smoking risks and motivation to quit among nontreatment-seeking smokers with and without schizophrenia. Schizophr. Bull. 2012; 38:543551. [PubMed: 21041835] A cross-sectional study which suggested that smokers with schizophrenia as compared to non-psychiatric smokers report greater reward perception and social facilitation, poor social pressure to quit smoking and less perception of tobacco-related health risks of smoking.

20. Ziedonis DM, George TP. Schizophrenia and nicotine use: Report of a pilot smoking cessation program and review of neurobiological and clinical issues. Schizophr. Bull. 1997; 23:247-254. [PubMed: 9165635]

21. Addington J, El-Guebaly N, Campbell W, et al. Smoking cessation treatment for patients with schizophrenia. Am J Psychiatry. 1998; 155:974-976. [PubMed: 9659869]

22. George TP, Ziedonis DM, Feingold A, et al. Nicotine transdermal patch and atypical antipsychotic medications for smoking cessation in schizophrenia. Am J Psychiatry. 2000; 157:1835-1842. [PubMed: 11058482]

23. Baker A, Richmond R, Haile M, et al. A randomized controlled trial of a smoking cessation intervention among people with a psychotic disorder. Am J Psychiatry. 2006; 163:1934-1942. [PubMed: 17074945]

24. Evins AE, Cather C, Culhane MA, et al. A 12-week double-blind, placebo-controlled study of bupropion SR added to high-dose dual nicotine replacement therapy for smoking cessation or reduction in schizophrenia. J Clin Psychopharmacol. 2007; 27:380-386. [PubMed: 17632223]

25. George TP, Vessicchio JC, Sacco KA, et al. A placebo-controlled trial of bupropion combined with nicotine patch for smoking cessation in schizophrenia. Biol Psychiatry. 2008; 63:1092-1096. [PubMed: 18096137]

26. Chou KR, Chen R, Lee JF, et al. The effectiveness of nicotine-patch therapy for smoking cessation in patients with schizophrenia. Int J Nurs Stud. 2004; 41:321-30. [PubMed: 14967189]

27. Evins AE, Mays VK, Rigotti NA, et al. A pilot trial of bupropion added to cognitive behavioral therapy for smoking cessation in schizophrenia. Nicotine Tob Res. 2001; 3:397-403. [PubMed: 11694208] 
28. Evins AE, Cather C, Deckersbach T, et al. A double-blind placebo-controlled trial of bupropion sustained-release for smoking cessation in schizophrenia. J Clin Psychopharmacol. 2005; 25:218225. [PubMed: 15876899]

29. Hurt RD, Sachs DPL, Glover ED, et al. A comparison of sustained-release bupropion and placebo for smoking cessation. N Engl J Med. 1997; 337:1195-1201. [PubMed: 9337378]

30. George TP, Vessicchio JC, Termine A, et al. A placebo controlled trial of bupropion for smoking cessation in schizophrenia. Biol Psychiatry. 2002; 52:53-61. [PubMed: 12079730]

31. Cahill K, Stead LF, Lancaster T. Nicotine receptor partial agonists for smoking cessation. Cochrane Database Syst Rev. 2008; 16:CD006103. [PubMed: 18646137]

32. Freedman R. Exacerbation of schizophrenia by varenicline. Am J Psychiatry. 2007; 164:1269. [PubMed: 17671295]

33. Popkin MK. Exacerbation of recurrent depression as a result of treatment with varenicline. Am $\mathbf{J}$ Psychiatry. 2008; 165:774. [PubMed: 18519539]

34 • Williams JM, Anthenelli RM, Morris C, et al. A double-blind, placebo-controlled study evaluating the safety and efficacy of varenicline tartrate for smoking cessation in schizophrenia and schizoaffective disorder. J Clin Psychiatry. 2012; 73:654-660. [PubMed: 22697191] The first multi-center double-blind, placebo-controlled evaluation of the safety and efficacy of varenicline for smoking cessation in smokers with schizophrenia and schizoaffective disorder.

35. Isensee B, Wittchen H, Stein MB, et al. Smoking increases the risk of panic: Findings from a prospective community sample. Arch Gen Psychiatry. 2003; 60:692-700. [PubMed: 12860773]

36. Zvolensky MJ, Forsyth JP, Fuse T, et al. Smoking and non-clinical panic attacks: An initial empirical test of panic-relevant cognitive processes. Cog Behaviour Therapy. 2002; 31:170-82.

37. Ziedonis DM, Hitsman B, Beckham JC, et al. Tobacco use and cessation in psychiatric disorders: National Institute of Mental Health report. Nicotine Tob Res. 2008; 10:1691-1715. [PubMed: 19023823]

38. Beckham JC, Roodman AA, Shipley RH, et al. Smoking in Vietnam combat veterans with posttraumatic stress disorder. J Trauma Stress. 1995; 8:461-472. [PubMed: 7582610]

39. Beckham JC, Kirby AC, Feldman ME, et al. Prevalence and correlates of heavy smoking in Vietnam veterans with chronic posttraumatic stress disorder. Addict Behav. 1997; 22:637-647. [PubMed: 9347066]

40. Op Den Velde W, Aarts PG, Falger PR, et al. Alcohol use, cigarette consumption, and chronic post-traumatic stress disorder. Alcohol Alcoholism. 2002; 37:355-361. [PubMed: 12107038]

41. McFall M, Saxon AJ, Thompson CE, et al. Improving the rates of quitting smoking for veterans with posttraumatic stress disorder. Am J Psychiatry. 2005; 162:1311-1319. [PubMed: 15994714]

42. Hertzberg MA, Moore SD, Feldman ME, et al. A preliminary study of bupropion sustained-release for smoking cessation in patients with chronic post-traumatic stress disorder. J Clin Psychopharmacol. 2001; 21:94-98. [PubMed: 11199956]

$43 \bullet$. McFall M, Saxon AJ, Malte CA, et al. Integrating tobacco cessation into mental health care for posttraumatic stress disorder: A randomized clinical trial. JAMA. 2010; 304:2485-2493. [PubMed: 21139110] A pivotal multi-center VA Cooperative Study comparing integrated versus separate mental health and tobacco treatment in smokers with post-traumatic stress disorder.

44. Prochaska JJ. Integrating tobacco treatment into mental health settings. JAMA. 2010; 304:25342535. [PubMed: 21139117]

45. Acton GS, Prochaska JJ, Kaplan AA, et al. Depression and stages of change for smoking in psychiatric outpatients. Addict Behav. 2001; 26:621-631. [PubMed: 11676374]

46. Haug NA, Hall SM, Prochaska JJ, et al. Acceptance of nicotine dependence treatment among currently depressed smokers. Nicotine Tob Res. 2005; 7:217-24. [PubMed: 16036278]

47. Breslau N, Johnson EO. Predicting smoking cessation and major depression in nicotine-dependent smokers. Am J Public Health. 2000; 90:1122-1227. [PubMed: 10897192]

48. Breslau N, Peterson EL, Schultz LR, et al. Major depression and stages of smoking. A longitudinal investigation. Arch Gen Psychiatry. 1998; 55:161-166. [PubMed: 9477930]

49. Weinberger AH, George TP, McKee SA. Differences in smoking expectancies in smokers with and without a history of major depression. Addict Behav. 2010; 36:434-437. [PubMed: 21239119] 
50. Thorsteinsson HS, Gillin JC, Patten CA, et al. The effects of transdermal nicotine therapy for smoking cessation on depressive symptoms in patients with major depression.

Neuropsychopharmacology. 2001; 24:350-358. [PubMed: 11182530]

51. Evins AE, Culhane MA, Alpert JE, et al. A controlled trial of bupropion added to nicotine patch and behavioral therapy for smoking cessation in adults with unipolar depressive disorders. J Clin Psychopharmcol. 2008; 28:660-666.

52. Hall SM, Tsoh JY, Prochaska JJ, et al. Treatment for cigarette smoking among depressed mental health outpatients: A randomized clinical trial. Am J Public Health. 2006; 10:1808-1814. [PubMed: 17008577]

53 •. MacPherson L, Tull MT, Matusiewicz AK, et al. Randomized controlled trial of behavioral activation smoking cessation treatment for smokers with elevated depressive symptoms. $\mathrm{J}$ Consult Clin Psychol. 2010; 78:55-61. [PubMed: 20099950] A well-designed randomized trial of a novel behavioral intervention for smoking cessation in depressed smokers.

54. Vickers KS, Patten CA, Lewis BA, et al. Feasibility of an exercise counseling intervention for depressed women smokers. Nicotine Tob Res. 2009; 8:985-995. [PubMed: 19541948]

55. Philip NS, Carpenter LL, Tyrka AR, et al. Varenicline augmentation in depressed smokers: An 8week, open-label study. J Clin Psychiatry. 2009; 70:1026-1031. [PubMed: 19323966]

56. Chengappa KNR, Kambhampati RK, Perkins K, et al. Bupropion sustained release as a smoking cessation treatment in remitted depressed patients maintained on treatment with selective serotonin reuptake inhibitor antidepressants. J Clin Psychiatry. 2001; 62:503-508. [PubMed: 11488359]

57. Trockel M, Burg M, Jaffe A, et al. Smoking behavior postmyocardial infarction among ENRICHD trial participants: Cognitive behavior therapy intervention for depression and low perceived social support compared with care as usual. Psychosom Med. 2008; 70:875-882. [PubMed: 18842753]

58. Weinberger AH, Vessicchio JC, Sacco KC, et al. A preliminary study of sustained-release bupropion for smoking cessation in bipolar disorder. J Clin Psychopharmacol. 2008; 28:584-587. [PubMed: 18794666]

59. Wu BS, Weinberger AH, Mancuso E, et al. A preliminary feasibility study of varenicline for smoking cessation in bipolar disorder. J Dual Diagnosis. 2012:131-132. *.

60. Weinberger AH, Sofuoglu M. The impact of cigarette smoking on stimulant addiction. Am J Drug Alcohol Abuse. 2009; 35:12-17. [PubMed: 19152200]

61. Hays JT, Schroeder DR, Offord KP, et al. Response to nicotine dependence treatment in smokers with current and past alcohol problems. Ann Behav Med. 1999; 21:244-250. [PubMed: 10626032]

62. Kalman D, Kahler CW, Garvey AJ, Monti PM. High-dose nicotine patch therapy for smokers with a history of alcohol dependence: 36-week outcomes. J Subst Abuse Treat. 2006; 30:213-217. [PubMed: 16616165] A large study of high-versus low dose transdermal nicotine for smoking cessation in smokers in early alcohol recovery.

63 - Kalman D, Herz L, Monti P, et al. Incremental efficacy of adding bupropion to the nicotine patch for smoking cessation in smokers with a recent history of alcohol dependence: results from a randomized, double-blind, placebo-controlled study. Drug Alcohol Depend. 2011; 118:111-118. [PubMed: 21507585] A large study comparing the addition of bupropion SR to transdermal nicotine for smoking cessation in smokers in early alcohol recovery.

64. Hays JT, Hurt RD, Decker PA, et al. A randomized, controlled trial of bupropion sustained-release for preventing tobacco relapse in recovering alcoholics. Nicotine Tob Res. 2009; 11:859-867. [PubMed: 19483180]

$65 \bullet \bullet$. Prochaska JJ, Delucchi K, Hall SM. A meta-analysis of smoking cessation interventions with individuals in substance abuse treatment or recovery. J Consult Clin Psychol. 2004; 72:11441156. [PubMed: 15612860] An outstanding meta-analysis of smoking cessation interventions in smokers with comorbid substance misuse that suggested the safety of concurrent versus sequential interventions for treating comorbid tobacco and other substance abuse.

66. Joseph AM, Willenbring ML, Nugent SM, Nelson DB. A randomized trial of concurrent versus delayed smoking intervention for patients in alcohol dependence treatment. J Stud Alcohol. 2004; 65:681-691. [PubMed: 15700504]

67. Nieva G, Ortega LL, Mondona S. Simultaneous versus delayed treatment of tobacco dependence in alcohol-dependent outpatients. Eur Addict Res. 2010; 17:1-9. [PubMed: 20881400] 
68. Hays JT, Croghan IT, Schroeder DR, et al. Varenicline for tobacco dependence treatment in recovering alcohol-dependent smokers: An open-label pilot study. J Subst Abuse Treat. 2011; 41:102-107. [PubMed: 20947286]

69. McKee SA, Harrison ELR, O'Malley SS, et al. Varenicline reduces alcohol self-administration in heavy-drinking smokers. Biol Psychiatry. 2009; 66:185-190. [PubMed: 19249750]

70. Nahvi S, Richter K, Li X, et al. Cigarette smoking and interest in quitting in methadone maintenance patients. Addict Behav. 2006; 31:2127-2134. [PubMed: 16473476]

71. Poling J, Rounsaville B, Gonsai K, et al. The safety and efficacy of varenicline in cocaine using smokers maintained on methadone: a pilot study. Am J Addict. 2010; 19:401-408. [PubMed: 20716302]

72. Okoli CTC, Khara M, Procyshyn RM, et al. Smoking cessation interventions among individuals in methadone maintenance: A brief review. J Subst Abuse Treatment. 2010; 38:191-199.

73. Moss TG, Weinberger AH, Vessicchio JC, et al. A tobacco reconceptualization in psychiatry: Toward the development of tobacco-free psychiatric facilities. Am J Addict. 2010; 19:293-311. [PubMed: 20653636]

74. Goff DC, Sullivan LM, McEvoy JP, et al. A comparison of ten-year cardiac risk estimates in schizophrenia patients from the CATIE study and matched controls. Schizophr Res. 2005; 80:4553. [PubMed: 16198088]

75. George TP, Ziedonis DM. Addressing tobacco dependence in psychiatric practice: Promises and pitfalls. Can J Psychiatry. 2009; 54:353-355. [PubMed: 19527555]

76. George, TP. Nicotine and Tobacco. In: Goldman, L.; Schafer, AI., editors. Goldman's Cecil Medicine. 24th edition. Elsevier Health Sciences Division; 2011. p. 142-146. 